\title{
Os elos entre a filosofia e a educação no pensamento de Theodor W. Adorno
}

Pedro Angelo Pagni*

\section{Resumo}

Este artigo aborda as relações entre a filosofia e a educação no pensamento de Theodor Adorno. A partir da reflexão elaborada pelo frankfurtiano acerca da relação entre teoria e práxis, procuramos compreender o papel político conferido às suas concepções de filosofia e de formação humana e discutir os seus limites e possibilidades no presente. Para tanto, elegemos como objeto de análise as conferências pronunciadas pelo autor e os artigos que escreveu sobre o assunto, entre 1959 e 1969, com o objetivo de recuperar os possíveis nexos teóricos entre filosofia e educação em sua obra e o significado que seu pensamento crítico e sua concepção de educação política assumiram nesse contexto; e de discutir sua eventual atualidade. Pretendemos, assim, reconstituir a reflexão de Adorno sobre o tema, compreendendo o seu significado em seu projeto filosófico, de modo a vislumbrar a face filosófica educacional de seu pensamento crítico.

\section{Palavras-chave}

Theodor W. Adorno; crise da formação humana; educação política; filosofia da educação.
* Professor de Filosofia da Educação no curso de Graduação em Pedagogia e no Programa de PósGraduação em Educação da Faculdade de Filosofia e Ciências e coordenador do Grupo de Estudos e Pesquisa em Educação e Filosofia da Unesp, Campus de Marília, SP, Brasil. Pesquisador do CNPq.pagni@terra.com.br 


\title{
The links between philosophy and education in Theodor W. Adorno's thoughts
}

\begin{abstract}
This article discusses the relationship between philosophy and education in Theodor Adorno's ideas. From the reflection about the relation between theory and praxis in his thoughts, we seek to understand the political role within his conceptions of philosophy and human formation and discuss limits and possibilities in the present. To this end, we selected for our object of analysis the conferences given by the author and articles he wrote on the subject, between 1959 and 1969, so as to recover the possible nexus between philosophy and theoretical education in his work, the meaning that his critical thinking and his conception of political education has taken in this context and to discuss how relevant this is nowadays. We therefore intend to reconstitute Adorno's reflection on the topicand understand its meaning in his philosophical project in order to see the educational philosophical aspect in his critical thinking.
\end{abstract}

\section{Key words}

Theodor W. Adorno; crisis of human formation; political education; philosophy of education. 
Em um artigo escrito após a morte de Theodor W. Adorno, Habermas (1993) presta uma última homenagem ao seu ex-professor. Ele relata que, algumas semanas antes de morrer, Adorno havia lhe contado uma história sobre o talento de Chaplin. Numa recepção aos atores do filme Os melhores anos de nossa vida, Adorno contou que, ao estender a mão para cumprimentar o ator que havia perdido as duas mãos na guerra, teria estremecido ao deparar-se com as duas garras da prótese metálica. Segundo ele, Chaplin teria reagido instantaneamente, ao presenciar a cena, traduzindo-a em pantomima e tentando dissimulá-la, em vão, ante o seu horror instintivo.

Para Habermas, essa história contada sobre Chaplin é, na verdade, a história do próprio Adorno. Ao longo de sua vida, ele teria se contraposto prática e teoricamente à frieza representada pela subjetividade burguesa, acreditando que fosse uma das responsáveis por situações como as de Auschwitz. Em decorrência disso, teria desenvolvido, com certo virtuosismo, uma "hipersensibilidade" que, antes do que um "olhar malévolo do misantropo", seria "o resíduo de uma ingenuidade não-exteriorizada e constantemente mobilizável” (Habermas, 1993, p. 139). Desse ponto de vista, o que a mímica do grande cômico teria conseguido naquele instante teria sido desfazer a tensão de um homem que, após o susto diante dos membros frios do ator, tentava recuperar o autocontrole. Esse teria sido um tema recorrente do discurso e das profundas análises contidas na obra filosófica e, mais do que isso, algo próprio do caráter de Adorno, que muitos teriam explorado em função de sua suposta ingenuidade.

A imagem retratada por Habermas valoriza o pensamento crítico e a importância de Adorno como um intelectual que viveu os problemas que pensou, contrapondo-se à desqualificação sofrida por ele em razão dos episódios com o movimento estudantili , ocorridos um pouco antes de sua morte. Assim, sugere certa coerência entre a ação e as opções teóricas de seu ex-professor, no contexto da época, e também certa ingenuidade, explorada largamente por aqueles que o acusaram de trair as posições de um intelectual de esquerda.

1. Refiro-me a uma série de manifestações dos estudantes, desde a de alunas que deixaram os seios à mostra em seus seminários como uma forma de protesto, provocando-lhe certo constrangimento, até o episódio da ocupação da reitoria, na ocasião em que era diretor do Instituto de Pesquisa Social, quando foi acusado de chamar a força policial para promover a desocupação. Em alguns textos e nas correspondências com Herbert Marcuse, organizadas por Loureiro (1999), a posição de Adorno em relação ao assunto parece se evidenciar, e a ela me refiro para circunscrever a sua ação intelectual ao contexto acadêmico-político do Pós-Guerra e, particularmente, ao momento de efervescência do movimento estudantil, em 1968 e 1969, na Alemanha. Isso porque os textos e parte da obra analisados nesta ocasião, com o intuito de reconstruir seus argumentos racionais, estão intrinsecamente relacionados a esse contexto de sua produção e devem ser considerados, mesmo que, em razão dos limites deste artigo, não seja possível reconstituí-lo historicamente. 
Ao centrar sua análise na crítica à razão subjetiva e na denúncia de que em sua gênese moderna reside o que denomina de autopreservação selvagem² ${ }^{2}$ Habermas elabora indicativos precisos sobre os eixos centrais em torno dos quais

2. Para Adorno, segundo Habermas (1993), por se pautar numa ideia de razão que se distingue da de natureza, esta última teria sido desconsiderada como parte constitutiva da primeira que, por sua vez, teria desprezado os mecanismos responsáveis por sua determinação imanente desde sua pré-história, ignorando os instintos de autoconservação que a fizeram se diferenciar, enquanto força psíquica, do princípio de identidade necessário à constituição do eu. Isso fez com que a razão subjetiva pudesse ser compreendida como idêntica a si mesma, negando 0 seu outro caracterizado pela natureza latente e esquecendo a dialética necessária à sua elaboração conceitual e à sua constituição enquanto tal. Nesse sentido, a razão subjetiva regrediria à própria natureza, em função de favorecer a própria autopreservação de um si mesmo conceitual, mas vazio; por isso, à mercê da natureza latente e selvagem, capaz de promover inadvertidamente as ações mais primitivas e bárbaras.

3. Originalmente, essa interpretação se disseminou na área de Ciências Humanas, no Brasil, graças a trabalhos como os de Bárbara Freitag (1986) e os de Sérgio Paulo Rouanet (1987). Na área de Educação, a interpretação veiculada por estes últimos não apenas foi parcialmente seguida por alguns estudos, como aparecem em trabalhos como os de José Pedro Boufleuer (1997) e de Maria Augusta Salin Gonçalves (1999), mas também foi reforçada em um sentido mais preciso e uma análise mais apurada do pensamento habermasiano, como se nota em alguns artigos de Werner Markert (1992) e, principalmente, de Pedro Göergen (1996). Essa tendência de interpretação parece ter sido revista por Goergen (2011), conjuntamente com o crescimento de uma análise do pensamento de Habermas mais centrada nas questões da interpretação, da racionalidade e da pragmática da linguagem, como as desenvolvidas por Nadja Hermann (1996) e por Ralf Ings Bannell (2006), promovendo um ponto de vista em que, não obstante as continuidades, as descontinuidades também são salientadas entre a primeira e a segunda geração da Teoria Crítica da Escola de Frankfurt. A emergência dessa revisão coincide com a interlocução dos estudiosos do projeto habermasiano com a obra de Gadamer, de Mead, dentre outras fontes de seu pensamento, por um lado; e com a emergência de uma série de estudos sobre os integrantes da primeira geração e as possibilidades de pensá-los na educação brasileira, por outro. gravitou o pensamento crítico de Adorno, fazendo jus ao rol de problemas por ele abordado; e auxilia a compreendê-lo como parte de uma ação intelectual consequente no contexto político-acadêmico do Pós-Guerra, na Alemanha. Contudo, ao problematizá-lo à luz de proposições caras ao desenvolvimento de seu projeto filosófico - como as relativas à subjetividade e à práxis -, o principal representante da segunda geração da Escola de Frankfurt interpela o pensamento adorniano a partir de sua posição, tomada como um ponto de vista superior à de seu antigo mestre, no que se refere à sua teoria da verdade. Embora haja uma tendência a conferir certo protagonismo a essa interpretação de Habermas³, também se desenvolveram várias outras, no Brasil - com estudos mais circunscritos ao pensamento de Adorno e de Benjamin ${ }^{4}$, que consideram o ponto de vista habermasiano não como um desdobramento destes, nem como superior a eles, mas como projeto filosófico distinto.

Particularmente, tenho me centrado em contribuir para essa segunda tendência interpretativa (Pagni; Silva, 2007), por vezes colocando o pensamento de Adorno em paralelo com o de outros filósofos contemporâneos ${ }^{5}$, com vistas não somente a revitalizar o seu projeto, como também a indicar a sua atualidade para pensar as questões emergentes do cenário cultural e educacional brasileiro. Graças a esse percurso 
de pesquisa, considero ser mais apropriado pensar essas questões a partir do pensamento de Adorno do que do de Habermas, além de considerar que aquele ocupa um lugar mais profícuo no debate político contemporâneo ${ }^{6}$. Seguindo essa linha interpretativa, retomo neste artigo somente a imagem e os eixos indicados nessa homenagem póstuma de Habermas ao seu ex-professor, e não integralmente a sua interpretação, para reconstruir um cenário a partir do qual pretendo elaborar uma reconstituição racional um pouco mais precisa, no que se refere ao seu contexto de produção, do pensamento adorniano. Nessa reconstrução racional do pensamento adorniano, objetivamos analisar a crítica da subjetividade moderna a partir da discussão do problema da relação entre sujeito e objeto, caro à Teoria do Conhecimento, e o da relação entre teoria e práxis, que se apresenta como chave para a compreensão de sua reflexão sobre a educação produzida entre 1959 e 1969. Recorremos, para tanto, a alguns artigos do livro Palavras e sinais (Adorno, 1995b), publicado nesse período, que aborda esses temas, assim como à coletânea Educação e emancipação (1995a). Por intermédio deste recorte, o artigo propõe-se a compreender o sentido educativo de sua filosofia e os pressupostos ético-filosóficos em que se assenta a sua concepção de educação, discutindo a hipótese de ser aquela uma forma de práxis teórica e esta uma face pouco explorada de seu pensamento, resultante de uma reflexão sobre a sua própria prática formativa no interior da universidade, escolhida estrategicamente por ele como meio de ação política nesse contexto histórico. Embora alguns trabalhos já tenham analisado os textos educacionais ou até mesmo os textos filosóficos circunscritos como objeto com propósitos semelhantes aos deste artigo, poucos foram os estudos que procuraram analisá-los com vistas a esse contexto da produção de sua

4. Protagonizaram a outra vertente interpretativa, no Brasil, os trabalhos de Olgária Matos (1989), de Rodrigo Duarte (1993) e de Jeanne Marie Gagnebin (1994). Na área da Educação, essa outra interpretação repercutiu a partir da tradução das conferências radiofônicas e dos debates de Adorno sobre a educação, por Wolfgang Leo Maar, publicados com o título Educação e emancipação, em 1995, pela Editora Paz e Terra, e de sua Teoria da Semicultura, por Newton Ramos de Oliveira, Bruno Pucci, Antônio Zuin, dentre outros, em 1996, publicado na revista Educação $e$ Sociedade. Este último grupo de pesquisadores também foi responsável pela difusão do pensamento da primeira geração da Teoria Crítica na Educação (Pucci; Oliveira; Zuin, 1998, 2000, 2001), juntamente com outras organizações individuais de Pucci (2003) ou coletivas (Pucci; Lastória; Costa, 2001; Pucci; Goergen; Franco, 2007; Pucci; Almeida; Lastória, 2009).

5. Consultar os paralelos que proponho de Adorno com Foucault (Pagni, 2006b, 2009a), com Lyotard (Pagni, 2005) e com Dewey (Pagni, 2009b).

6. Em outra ocasião, ao reconstruir o debate em torno da pós-modernidade, desenvolvi esse argumento (Pagni, 2006a) que, em razão dos limites deste artigo, resumo brevemente aqui. Argumentei que, ao defender-se das acusações de Habermas sobre seu suposto neoconservadorismo, estrategicamente, Foucault retomava o pensamento da primeira geração da Teoria Crítica e, particularmente, a sua suspeita da modernidade, para assinalar as proximidades com os integrantes desse movimento e para defender que nos projetos filosóficos destes se delineava uma atitude crítica radical em relação ao presente, supostamente abandonada por Habermas. Esta interpretação foi responsável pela circunscrição do artigo nos termos apresentados a seguir. 
perspectiva filosófico-educacional7 que, em tese, poderia torná-la mais precisa e, ao mesmo tempo, apropriada para discutir a sua atualidade. Recordar esta face de seu pensamento foi o modo escolhido neste artigo para explicitar a perspectiva filosófico-educacional compreendida pelo pensamento desse teórico da Escola de Frankfurt.

\section{A filosofia como uma práxis teórica e o seu sentido ético-educativo}

No livro Palavras e sinais (1995b), Adorno aborda os limites da subjetividade moderna e da teoria do conhecimento por ela influenciada, à luz do que entende ser o pensamento filosófico. Adorno (1995b) argumenta que o pensar filosófico teria se tornado presa da coisificação, na medida em que se autonomizou do pensado e se tornou autocrático, traduzindo-se em fórmulas e funcionando como uma espécie de aparelho, comparável aos computadores. Contrapondo-se a essa formalização, Adorno afirma que o pensar filosófico "só começa quando não se contenta com os conhecimentos que deixa abstrair e dos quais nada mais se retira além daquilo que se colocou neles" (Adorno, 1995b, p. 16).

7. Um dos artigos que protagonizou a temática foi o de Bruno Pucci (1998), e esta, a meu ver, apenas recentemente foi retomada, com o aprofundamento devido, na tese de doutorado de Franciele Bete Petry (2011), orientada por Alexandre Fernandez Vaz. Graças a essa tese, pude reavaliar o valor de um artigo ainda inédito e reformulá-lo para esta publicação, pois pude perceber que a grande recepção da primeira geração da Teoria Crítica da Escola de Frankfurt no campo da Educação no Brasil, da década de 1990 até hoje, ainda não havia esgotado 0 assunto, havendo outras possibilidades de explorá-la. Se a tese de doutorado em questão explorou o tema das relações entre educação e filosofia, recorrendo aos livros Dialética do esclarecimento e Dialética negativa, optei por explorá-la por meio da análise de alguns artigos e ensaios considerados periféricos à obra de Adorno, já que entendo que se referem a um contexto específico de sua produção, profícuo para evidenciar, ainda mais, a face filosófico-educacional de seu projeto intelectual. Nisto parece residir certa originalidade desta abordagem do tema, se comparada com as produções anteriormente citadas, juntamente com a pretensão de fornecer algumas pistas sobre a discussão acerca do papel exercido por esse intelectual na ação formativa desenvolvida em seu contexto e, quem sabe, a reflexão sobre a ação que desenvolvemos como educadores na atualidade.
0 pensar, como revelara Kant, seria uma atividade espontânea e passiva, mas, por trás desse momento de passividade, haveria uma apercepção original a respeito de um objeto indeterminado que seria determinado pelas próprias faculdades formais do sujeito. Nesse sentido, não haveria objetividade no pensar filosófico, mas uma entrega ao objeto pensado que, por sua vez, consistiria no reconhecimento da determinação subjetiva e na comunicação daquilo que não seria objetivo no processo de conhecimento. Seriam justamente esses os limites da teoria do conhecimento tradicional e da subjetividade moderna evidenciados no ensaio de Adorno (1995b) sobre a relação entre o sujeito e o objeto, no qual defende um pensar filosófico como uma crítica subjetiva que busca evidenciar esse outro do conhecimento dito obje- 
tivo. Dessa forma, o frankfurtiano procura problematizar a identificação do objeto ao sujeito, imprimida pelo positivismo e pela teoria do conhecimento tradicional, assim como redefinir o papel desempenhado pelo pensamento filosófico na atualidade.

Mais precisamente, por meio desse movimento que se apoia na crítica filosófica, Adorno (1995b) postula levar o sujeito que conhece a deparar-se com seus próprios limites, seguindo a regra da primazia do objeto. Para tal propósito, coloca a própria subjetividade como objeto do pensar filosófico do sujeito e, na medida em que concebe este último para além da dicotomia entre o transcendental e o empírico, convida o próprio indivíduo pensante a uma autorreflexão crítica. É este último movimento que procura levar o sujeito à reflexão sobre seu próprio formalismo e sobre os limites que aprisionam a sua subjetividade, concebidos pelo frankfurtiano como o meio privilegiado para que, no presente, se exerça a crítica sobre os mecanismos sociais e políticos que ocasionam esse formalismo e se resista à dominação exercida pela sociedade existente. Nesse movimento em direção a si mesmo, o sujeito encontraria as formas subjetivas e objetivas de sua dominação, exigidas para o conhecimento objetivo e para a transformação dos outros homens e de si mesmo em algo manipulável, em objeto da sociedade existente. E nele, também, o indivíduo encontraria a liberdade ainda possível ao sujeito e ao pensamento filosófico, a saber: comunicar o indiferenciado que o conhecimento objetivo não é capaz de identificar, torná-lo próximo e presente, a fim de evitar a violência contra o objeto e contra os que nele se converteram na sociedade atual, seja em nome da Razão, seja em nome da ciência.

Nesse sentido, o frankfurtiano procura redefinir o agente mediador entre a teoria e a prática, embora sem muito sucesso. Isso porque ele não se propõe a formular uma nova figura do sujeito nem da subjetividade, mas opera criticamente com os conceitos tradicionais, elucidando os seus limites teóricos e de seu pensamento no mundo atual; sua incapacidade de experiência, comunicando-os àqueles que ainda estejam dispostos a uma forma de autorreflexão crítica e convidando esses indivíduos a desempenhar uma forma de resistência à reificação da consciência. Assim, contempla uma prática, mesmo quando trata de uma questão eminentemente teórica, como que tentando convencer os que veem essa questão do conhecimento como algo independente daquela e do pensamento filosófico.

Por essa razão, Adorno (1995b, p. 202) escreve: "Até que ponto a questão relativa à teoria e práxis depende da relativa a sujeito e objeto, evidencia-se por uma simples reflexão histórica”. Refere-se tanto à separação entre teoria e prática instaurada pela 
metafísica, com o privilégio da primeira sobre a segunda, quanto às correntes filosóficas que a ela se contrapuseram, como o pragmatismo, utilizando como critério de conhecimento a utilidade prática. De acordo com ele: "A teoria só se libertaria desta imanência onde se desprendesse das cadeias do pragmatismo, por mais modificadas que elas estejam" (Adorno, 1995b, p. 203). Contudo, a recusa da teoria e do imobilismo provocado pelo pensar filosófico ou pela filosofia pura em nome da prática ou da ação que permitiriam ao indivíduo burguês restituir-se enquanto tal, por intermédio de uma concepção de autoalienação similar à do romantismo alemão, seria adequada ao problema da práxis atual. No seu entender, tal situação "coincide com a perda da experiência causada pela racionalidade do sempre-igual” (Adorno, 1995b, p. 203). Isso porque, para ele, onde a experiência fosse interditada ou, simplesmente, não ocorresse, a práxis seria "danificada e, por isso, ansiada, desfigurada, desesperadamente supervalorizada” (Adorno, 1995b, p. 203-204), estando neste ponto entrelaçada com o problema do conhecimento.

Se, por um lado, tal entrelaçamento do conhecimento com a prática se tornou uma das aspirações do pensamento filosófico e concorreu para a sua restrição a uma racionalidade instrumental, por outro, a postulação de que a salvação da Filosofia, diante da perda da capacidade de fazer experiência, estaria no trabalho em relação ao conceito também se tornou problemática. Isso porque este último postulado projetou um pensamento especulativo que não somente foi incapaz de diagnosticar a deterioração da experiência humana, como também concorreu para que o pensar filosófico fosse compreendido como a aplicação do conceito imediatamente à prática e como uma elaboração teórica capaz de justificá-la. Mesmo que isso significasse o contrário da liberdade e da autonomia prometidas por esse discurso moderno no qual se apoiou a Filosofia, esse pensar filosófico teria concorrido, assim, para que o mundo permanecesse praticamente o que é, enquanto teoricamente se postulasse sua transformação. No mundo atual, o que alterasse essa ordem de coisas - sobretudo, aquilo que pleiteasse fazer a teoria uma forma de ação - seria "amputado do pensar". Afinal, diz Adorno, pensar "é um agir, teoria é uma forma de práxis", que "somente a ideologia da pureza mistifica este ponto" (1995b, p. 204). Nesse sentido, o pensar "tem duplo caráter: é imanentemente determinado e é estringentemente e obrigatório em si mesmo, mas, ao mesmo tempo, é um modo de comportamento irrecusavelmente real em meio à realidade" (Adorno, 1995b, p. 205).

Se o sujeito se torna objeto do pensar filosófico, nos termos anteriormente salien- 
tados, conclui Adorno (1995b, p. 205), “ele é, de antemão, também prático”. Não obstante a irracionalidade "sempre novamente emergente da práxis" anime uma separação entre sujeito e objeto, a simulação de que o objeto é “incomensurável em relação ao sujeito, um cego destino captura a comunicação entre ambos" (Adorno, 1995b, p. 205). Na acepção adorniana, o pensar filosófico deveria se dedicar à perquirição desse cego destino e à comunicação da diferenciação entre sujeito e objeto, assumindo a tarefa de promover a reflexibilidade subjetiva para que o sujeito empírico encontre onde, quando e em que sentido deve intervir, ativamente, ainda que seja para negar e conter eticamente o que de destrutivo há em si mesmo.

Fazendo essa opção pela teoria enquanto uma forma de práxis e pelo pensar como um modo de agir ético, o autor contrapõe-se não apenas ao pragmatismo, como também ao ativismo decorrente de uma persistência de uma práxis política sem as devidas mediações. Nas correspondências entre Adorno e Marcuse, selecionadas por Loureiro (1999), as alusões à prática do movimento estudantil alemão expressa no contexto pós-1969 são evidentes, nomeando precisamente essa forma de praticismo político, sem mediações teóricas e sem uma ação consciente por parte de seus sujeitos. No âmbito de seu projeto filosófico, no mesmo período, argumenta que, na relação entre teoria e práxis, a teoria interpreta a situação existente, sem buscar uma adaptação a ela, e funciona como uma espécie de força produtiva prática, autônoma, que sempre alcança algo importante e produz um impulso prático por intermédio do pensamento. Nesse sentido, o frankfurtiano considera que só pensaria aquele que não se limitasse a aceitar o dado e que encontrasse sua maior força na teoria, independentemente do ensejo prático almejado. Isso significa admitir que o pensamento possuiria um telos prático e que meditar sobre a liberdade seria pensar na sua possível produção, desde que isso não implicasse em uma limitação prática concebida a priori ou em uma medida predefinida ou encomendada de resultados. Assim, as divisões entre sujeito e objeto, teoria e práxis não poderiam ser reconciliadas arbitrariamente pelo pensamento filosófico, como num passe de mágica, sob o risco de derrotar, na acepção de Adorno, o interesse da "verdadeira práxis" (1995b, p. 210).

Se, antes, o conteúdo de verdade desse discurso que procurou ligar teoria e práxis tinha algum significado diante das condições históricas, no contexto em que vive o frankfurtiano e em que vivemos nós, "a aversão à teoria constitui a fragilidade da práxis" (Adorno, 1995b, p. 213). Para o frankfurtiano, a pressa em transformar o mundo, sem interpretá-lo, teria resultado no impedimento dessa mesma transformação e na 
justificativa das atrocidades cometidas contra o próprio homem. Diante dessa situação, uma "práxis oportuna seria unicamente a do esforço de sair da barbárie" (Adorno, 1995b, p. 214), pois esta se estendeu e contagiou praticamente toda a sociedade e as disposições subjetivas dos que a sustentam, chegando a um ponto extremo.

Aquilo que, há cinqüenta anos, ainda poderia parecer justo por um breve período, a esperança demasiadamente abstrata e ilusória de uma transformação total, - a violência - encontra-se depois da experiência do horror nacional-socialista e stalinista, e frente à totalidade da repressão totalitária, inextricavelmente enredado àquilo mesmo que deveria ter sido mudado. Se o contexto culposo [Schuldzuammenhang] da sociedade e, com ele, as perspectivas de catástrofe tornaram-se deveras totais - e nada permite duvidar disso -, assim nada é possível contrapor-lhe a não ser aquilo que denuncia esse contexto geral de ofuscamento [Verblendungszusmmenhang], ao invés de participar nele com suas próprias forças. $\mathrm{Ou}$ a humanidade renuncia ao olho por olho da violência, ou a práxis política supostamente radical renovará o velho horror. (Adorno, 1995b, p. 214-215).

Tanto para o problema do conhecimento quanto para o da práxis, Adorno insiste que o sujeito e o pensamento filosófico deveriam buscar uma reconciliação com o objeto e assim se constituírem em legítimos mediadores da relação entre a teoria e a práxis. Isso significa que o pensamento filosófico, ao invés de arbitrariamente promover uma identificação entre sujeito e objeto, assim como entre a teoria e a prática, deveria enfocar o outro do objeto e da práxis. Nesse sentido, ocorreria uma inflexão do pensamento sobre a subjetividade e sobre a teoria na qual se sustenta, a fim de alvejar o seu núcleo e, indefinidamente, buscar seu conteúdo de verdade.

O conteúdo de verdade da subjetividade não seria outra coisa, no presente, senão o sentimento de compaixão pela miséria, pela dor e pelo sofrimento alheios. 0 mesmo sentimento, ignorado tanto pela racionalidade instrumental quanto pelo pensamento especulativo, instituído em nome da verdade contida nos conceitos, do esvaziamento da cultura; em nome da civilização e do esquecimento pela práxis; em nome da adaptação ao existente ou, mesmo, de uma transformação social. Ao ser ignorado, suprimido e esquecido nesses termos, porém, a perda de tal sentimento fez com que 
a razão subjetiva se convertesse em racionalidade instrumental e os conceitos perdessem a sua substancialidade, ao ponto de transformar a verdade em ideologia. Dessa forma, a cultura converteu-se em semicultura, e, consequentemente, a própria civilização alimentou sua tendência à barbárie; a práxis reflexiva foi abandonada, e a reflexão teórica, que antes a impulsionava, se converteu num ativismo cego, em que a crítica e o pensamento filosófico foram prescritos em nome da paranoia coletiva.

0 frankfurtiano denuncia, assim, a subjetividade burguesa e a frieza que acompanhou o discurso filosófico da modernidade, desde sua gênese moderna, insistindo na verdade que poderia representar, caso se tornasse autoconsciente do outro que acompanha a sua formação cultural (Bildung) no Ocidente. A verdade na qual insiste Adorno não é aquela pensada em termos metafísicos, e, sim, uma espécie de mensagem que seja capaz de mobilizar nos homens aquilo que ainda lhes resta de humano, o sentimento de compaixão pela miséria, pela dor e pelo sofrimento alheios.

Embora utilizada em diversas de suas obras para mobilizar seus leitores, essa estratégia não consiste propriamente num critério de verdade para o frankfurtiano, pois isso significaria uma versão metafísica do materialismo. Contudo, ao que tudo indica, essa estratégia consiste num sentido ético e político a ser levado em conta pelo seu pensamento filosófico e, quem sabe, o seu sentido educativo par excellence. É como se ética e teoria do conhecimento caminhassem juntas no pensamento adorniano e funcionassem como uma forma de resistência à mínima moral existente no mundo contemporâneo e à ausência da crítica no conhecimento científico atual. Mas, então, como Adorno justificaria essa resistência e esse pensamento crítico? Na interpretação de Habermas:

Adorno recusou-se tenazmente a propor uma solução afirmativa. Contestou, igualmente, que a negação do sofrimento vivido constituísse um critério de validade dessa crítica. Tal negação não teria qualquer referente, no sentido exigido pela negação determinada de Hegel. E, no entanto, Adorno está sujeito à compulsão sistemática de recorrer à idéia de reconciliação. Não pode livrar-se dela: pois, quando o sofrimento é sublimado de forma a transcender a dor física imediata, ele só pode ser negado quando ficar manifesto, ao mesmo tempo, tudo o que foi reprimido pela objetividade da coação social. (Habermas, 1993, p. 146-147). 
Habermas afirma ainda que Adorno teria pensado nessa ideia de um sujeito reconciliado com seu objeto, do indivíduo reconciliado com o todo social, onde encontraria a felicidade objetiva, mantendo o que the fosse "estranho" (a miséria, a dor e o sofrimento alheios) sempre à vista, de um modo distanciado e distinto, mas próximo de si mesmo. Ao não pensar positivamente como isso poderia ser comunicado pelo sujeito e pelos indivíduos num contexto de não violência, segundo ele, Adorno haveria pensado isso a partir da ideia de emancipação (Muendigkeit), como uma "metáfora que é possível aludir à reconciliação, e assim mesmo porque essa metáfora obedece à proibição da imagem e, por assim dizer, anula-se a si mesma" (Habermas, 1993, p. 147).

Essa interpretação parece ser procedente quanto à afirmação de que o critério de verdade do pensamento crítico adorniano teria sido expresso na forma de metáfora, utilizando como ilustração a obra Dialética do esclarecimento (Adorno; Horkheimer, 1986). Isso porque, no contexto em questão, a persistência de Adorno em apostar na possibilidade da emancipação humana - mesmo que para os indivíduos que ainda não se encontrem completamente contaminados pela "frieza burguesa" e com suas consciências reificadas - se relaciona a sua insistência em retomar, pela via crítica, a própria filosofia e retomar também a capacidade educativa do lluminismo (Aufklärung). Essa possibilidade aparece esboçada tanto no ensaio "Filosofia, para quê?”, quanto na famosa conferência “Educação após Auschwitz”. Em ambos, Adorno $(1969,1995$ b) explicita que a única tarefa possível para a filosofia e a educação seria a de evitar a repetição da barbárie por meio de uma inflexão crítica em direção ao sujeito ou de uma autorreflexão crítica, no sentido de reconhecer em si o outro da razão e da consciência que promoveriam a destruição, o ódio e o ressentimento que levaram ao totalitarismo.

Embora Adorno tome a ideia de emancipação contida nessa tradição, o faz como uma metáfora e como uma forma de crítica. Por isso, retomou as ideias de emancipação humana e de autonomia do pensamento da tradição iluminista alemã para cobrar as promessas nelas contidas que não foram realizadas e para diagnosticar que elas resultaram em mera ideologia. No presente, tal ideologia não apenas corrobora o ajustamento do indivíduo ao existente e a heteronomia de seu pensamento na sociedade administrada, como também concorre para que a racionalidade instrumental e o princípio de dominação, nos quais se fundamentam e se encontram prefigurados na gênese daquelas ideias modernas de emancipação e autonomia, preponderem 
em sua concretude no mundo existente. É no âmbito de uma contraposição ferrenha aos moldes de uma educação para a dureza e para a severidade, porém, que Adorno (1995a) parece recuperar a tradição da pedagogia da Aufklärung pelos seus efeitos negativos sobre a realidade educacional. Para o frankfurtiano, nenhuma fórmula, em termos pedagógicos, reforçaria tanto a disseminação da racionalidade instrumental e da frieza burguesa como a da educação para a virilidade, para a disciplina e a severidade. Afinal, nela se encontraria a identificação com práticas em que a capacidade de suportar a dor seria premiada, provocando uma indiferença à dor e ao sofrimento alheios, pois diz Adorno: "Quem é severo consigo mesmo adquire o direito de ser também com os outros, vingando-se da dor cujas manifestações precisou ocultar e reprimir" (1995a, p. 128). Ao se contrapor à educação para a severidade, como ponderaram Pagni e Silva (2007), o frankfurtiano parece deixar claro que não pensa em retornar à educação moral tradicional nem em endossar a sua conversão em mera tecnologia, mas em problematizar radicalmente e evitar os seus efeitos nefastos, na contemporaneidade.

Especificamente, a formação de homens que tratam os outros como coisas, aprimorando o caráter manipulador e acentuando os traços de uma personalidade autoritária das pessoas, deve ser evitada, do mesmo modo que a indiferença gerada pela adoração e pelo uso da tecnologia, responsável pela constituição de seres tecnológicos. Em contraposição a esses efeitos da educação para a severidade e de sua configuração atual, o frankfurtiano propõe uma educação que, ao ser iniciada na primeira infância, seja capaz de tornar as pessoas mais sensíveis à dor e ao sofrimento alheios e de formar sujeitos capazes de criticar o mundo e a si mesmos, por meio de um conjunto de estratégias que, como veremos a seguir, vão da crítica teórica à semiformação, até a sensibilização dos indivíduos, passando pela atuação interdisciplinar de vários campos do conhecimento. Esta seria a possibilidade de manter vivo o espírito da pedagogia da Aufklärung no presente.

\section{A crise da formação cultural e as possibilidades atuais da educação política}

Procedimento semelhante ao exposto anteriormente é adotado por Adorno, quando reflete sobre a formação cultural (Bildung), insistindo em seu conceito tradicional como uma forma de crítica à sua perda de sentido, entendida por ele como um sinal de sua "necrose" e da "universalização da semicultura (Halbbildung)" na socieda- 
de atual. Este é o modo pelo qual, em sua "Teoria da Semicultura”, Adorno refaz a gênese e o desenvolvimento da Bildung na sociedade moderna e contemporânea, denominando de Halbbildung o seu "espírito objetivo negativo" (Adorno, 1996, p. 388). Considerando que, na socialização da Halbbildung atual, os indivíduos teriam incorporado e associado, mesmo, aos seus anseios inconscientes - que a civilização fez questão de reprimir -, elementos que impediriam a correção da crise da Bildung, Adorno ainda insiste em cobrar as promessas contidas no seu conceito tradicional. A saber, a de que a Bildung pressupunha a formação de uma consciência verdadeira, pautada na autonomia do pensamento e na liberdade moral que caracterizam o que se denomina de sujeito e constituem a subjetividade ou, simplesmente, a personalidade.

É certo que Adorno (1996) não concorda com esses ideais transcendentes em que se funda a Bildung, tanto que procura compreendê-los a partir de sua constituição na sociedade, criticando-os e recorrendo, mesmo, ao seu caráter empírico. Repensa-os, assim, a partir de instrumentos capazes de elucidar para as próprias pessoas e os tipos sociais que estão imersos na socialização da Halbbildung atual, os mecanismos objetivos e subjetivos que a promovem na sociedade atual.

Uma das maneiras sugeridas por Adorno para contestar os mecanismos subjetivos que promovem a Halbbildung e que se enraízam, mesmo, no inconsciente das pessoas seria tratá-los por intermédio da "psicologia profunda". Esta última poderia contribuir para, desde os primeiros anos da infância, afrouxar os bloqueios e fornecer os primeiros elementos para a consciência crítica. Todavia, dever-se-ia reconhecer que tal situação não poderia ser solucionada apenas subjetivamente, pela esfera da consciência atual, já que esta seria impotente frente à tendência objetiva que a determina e ao aniquilamento mesmo dos pressupostos da Bildung autêntica, pela indústria cultural e pelo nivelamento da consciência produzido por ela (Adorno, 1996, p. 408). Foi por essa crítica, orientada pela lembrança das promessas contidas no conceito de Bildung tradicional e que foram esquecidas pelas teorizações acerca de sua crise atual, que o frankfurtiano apresentou os paradoxos compreendidos por qualquer tentativa de esboço de novas teorias sobre o assunto. Assim, Adorno insistiu na "autoconsciência do espírito" que, afinal, caracterizou a filosofia que a formulou e na crítica empreendida pelos seus opositores, materialistas, não para superar esta situação agravada com a Halbbildung socializada, mas para resistir a ela, por intermédio de uma "teoria da semicultura", isto é, de uma teoria que deveria apontar para uma situação em que: 
[...] a cultura nem fosse sacralizada, conservada em seus restos, nem eliminada, porém que se colocasse além da oposição entre cultura e não cultura, entre cultura e natureza. Isto, porém, requer que não somente se rejeite uma concepção de cultura tomada como absoluta, como também não se dogmatize, que não se enrijeça sua interpretação em tese não dialética como algo dependente, como mera função da práxis e mero voltar-se a ela. (Adorno, 1996, p. 409).

Essa posição de Adorno consiste em não retomar o idealismo que pretende uma autonomia absoluta do espírito em relação à produção material nem endossar as teses materialistas que o consideram como determinado economicamente. Significa, ante o fracasso das soluções apontadas por essas correntes do pensamento, insistir em sua reflexão teórica, pela crítica à Halbbildung atual, capaz de resistir ao aniquilamento da cultura e da barbárie por ela produzida. Ainda que não seja possível a superação dos mecanismos objetivos - sociais e políticos - que a determinam, nem mesmo por uma praxis revolucionária, em razão da integração da consciência, segundo Adorno (1996, p. 409-410), ao menos se pode insistir no fortalecimento dos mecanismos subjetivos capazes de promover a resistência diante desta situação e levar aqueles que ainda não estão totalmente imersos no sistema a uma "autorreflexão crítica" sobre a Halbbildung.

Este é o ponto central de sua "teoria da semicultura". Ele supõe a elaboração de uma teoria negativa a respeito da própria Bildung, que revele sua degradação e o seu outro, a Halbbildung, buscando uma tensão entre natureza e cultura, que pode ser percebida, por alguns indivíduos, por suas experiências, e autorrefletida em sua subjetividade. Tal teoria entende que, em tal processo de mergulho na subjetividade, os indivíduos encontram uma tendência para sua dissolução subjetiva, para a qual concorre a Halbbildung e na qual se percebe a coação social exercida pela socialização desta última, expressa no sofrimento que provoca e no aumento da pressão do todo social que representa. Por meio de tal autorreflexão crítica sobre si mesmo, ainda, o ressentimento que esta tendência promove e o risco em que coloca a própria cultura, ao serem evidenciados, poderiam tornar conscientes tanto a submissão de sua natureza à cultura estereotipada e à ilusão da sociedade homogênea quanto as prováveis razões da revolta daquela natureza interna sobre estas mesmas cultura e sociedade. É desse modo que o indivíduo poderia experimentar em si mesmo as consequências 
da Halbbildunge, tentar evitar que esta alimentasse a destruição da cultura. Assim, essa "teoria da semicultura", menos do que pretender-se legítima frente aos rígidos cânones do saber científico que se dedicam a estudar a crise da Bildung, procura refletir criticamente o seu objeto mesmo e, com isso, promover seu sentido educativo, levando os indivíduos à percepção da degradação de sua própria subjetividade e ao vislumbre do que the resta de capacidade de experiência.

Diante do exposto, o questionamento de Marcuse (1999) ao estilo de Adorno comunicar a radicalidade do pensamento parece bastante pertinente, principalmente, caso se considere sua produção teórica - os dois ensaios filosóficos contidos no $\mathrm{Pa}$ lavras e sinais (1995b) e o livro Dialética negativa (2009) - ou, mesmo, aquela decorrente das notas de aula ou dos seminários de filosofia oferecidos pelo Instituto de Pesquisa Social - como Terminologia filosófica (1983) e Três estudos sobre Hegel (1991) - durante o período em questão. Vale lembrar, ainda, a passagem de um artigo em que Adorno (1995a, p. 72-73) recomenda a leitura do método de estudo acadêmico de Schelling, dizendo ter-se inspirado nele para ser um professor de filosofia que, raramente, recebe elogios de seus alunos em função da capacidade de comunicar didaticamente o pensamento, tornando simplificada a realidade, mas justamente por comunicar o pensamento como ele é e expressar a complexidade necessária à reflexão da coisa mesma. Nesse sentido, procura combater a cultura da facilidade, o pedagogismo e o didatismo, em sua atividade docente, contrapondo-se à semicultura socializada e à qualificação profissional produzida na universidade, ponderando que o esforço ainda é necessário à formação acadêmica, e esta não simplificaria a realidade, mas a compreenderia em sua complexidade.

Formar para a complexidade consiste aqui numa resistência política à semicultura (Halbbildung) e à qualificação profissional (Ausbildung), vigentes na universidade, que à época tinha abandonado completamente o ideal de Bildung. Pensar esse ideal criticamente e promover uma ação política imanente à prática formativa desenvolvida no interior da universidade, nos termos apresentados, parece caracterizar uma escolha estratégica feita pelo frankfurtiano, que reforça a sua opção pela teoria, mas entendendo-a como forma de práxis.

Se essa ação política está implícita nas discussões que produz em relação ao ensino universitário, ela aparece de modo explícito em outras conferências sobre a educação, destacando o seu caráter eminentemente político. É o que se verifica em uma de suas conferências sobre a educação, quando ele indica a necessidade de uma 
reeducação e de uma forma de educação política que sirva como uma resistência à situação existente.

Após mostrar que a Aufklärung teria sido responsável pela destruição da memória e pela não elaboração do passado, experimentadas pela consciência atual, ele critica o fato de que o seu desenvolvimento educativo tivesse servido à sobrevivência do nazismo na democracia. Embora reconheça o pessimismo exagerado dessa tese, considera que "hoje em dia somente o exagero consegue veicular a verdade" (Adorno, 1995a, p. 44). Argumentando que, nos países onde a "educação política" teria sido levada a sério - como o mostra a sociologia da educação -, a resistência ao nazismo tinha sido maior, o frankfurtiano a considera como algo interessante e que deveria ser ampliada, a fim de investigar suas possibilidades no mundo atual. Reconhece que, ante o perigo objetivo da sobrevivência do nazismo na democracia, porém, a insistência de uma pedagogia da Aufklärung seria limitada, sendo possível somente àqueles que estivessem abertos a ela, ou melhor, àqueles que se fecharam ao fascismo. Critica, desse modo, os limites da pedagogia da Aufklärung, retomando os seus próprios elementos, insistindo em suas promessas, como diz ele, nem que seja como um meio de reforçar em um grupo pequeno sua resistência contra a "opinião não-pública" e, gradativamente, estender aos outros a Aufklärung (Adorno, 1995a, p.45).

A insistência na realização da pedagogia da Aufklärung deveria começar com a elaboração do passado, ainda que essa insistência possa gerar ódio contra os que a formulam, aumentando ainda mais a resistência contra ela. Tal iniciativa poderia fazer com que as pessoas, segundo ele, venham a sentir uma infelicidade maior do que o mal-estar e as tensões psíquicas acumuladas em seu conformismo. Adorno argumenta que, mesmo que não queira dar uma resposta definitiva à questão, "0 consciente jamais se relaciona à infelicidade nos mesmos termos em que isto ocorre com o inconsciente e com o pré-consciente" (Adorno, 1995a, p. 46). Sendo assim, continua ele, "tudo dependerá do modo como o passado será referido no presente; se permanecemos no simples remorso ou se resistimos ao horror com base na força de compreender até mesmo o incompreensível” (Adorno, 1995a, p. 46).

Notamos aí certa diferenciação entre a discussão sobre o ideal de Bildung e a formação universitária no pensamento adorniano. Ele não formula uma teoria negativa a respeito de um dado objeto a partir do pensamento crítico em que se baseia a sua filosofia, dando a ela um sentido pedagógico implícito. Ao contrário, a partir dessa filosofia, aborda e coloca problemas comuns ao campo pedagógico e educacional, focalizando 
aqueles eminentemente práticos, e arrisca algumas sugestões concretas para a sua superação. Embora essas sugestões nunca tenham um sentido afirmativo, esse conjunto de conferências e entrevistas sobre a educação sinaliza para algo diferente da fixação na teoria e da crítica, que caracterizam o projeto filosófico adorniano nos anos 1960.

Diante das dificuldades anteriormente esboçadas, diz Adorno (1995a, p. 46), a pedagogia deveria abandonar o seu "palavrório melancólico de segunda mão sobre o ser dos homens" e assumir "a tarefa cujo tratamento insuficiente se critica tanto na reeducation (reeducação)". Nesse sentido, entende que a pedagogia deveria fortalecer a posição de uma sociologia que se detenha na "pesquisa histórica sobre nossa época”, bem como se aproximar, ou reaproximar, da psicanálise (Adorno, 1995a, p. 46). Assim, em resumo, o autor coloca em xeque os pressupostos e os ideais que orientaram a teoria e a prática educacional até então, dando a eles outro contorno e delimitação, não tanto para reorientá-las concretamente, mas, sim, apresentando outros problemas para serem enfrentados e pesquisados.

Adorno sugere que, ao menos, o que restou da pedagogia da Aufklärung possa promover uma "inflexão em direção ao sujeito, reforçando a sua autoconsciência e, por esta via, também o seu eu” (Adorno, 1995a, p. 47). Dessa forma, o autor insiste na elaboração do passado pressuposta por uma "educação política” para a democracia, retomando o problema da subjetividade evanescente e uma antiga figura do sujeito que é procurada todo momento em seu pensamento. Todavia, nessa face educativa de sua obra, essa crítica é utilizada para circunscrever problemas pedagógicos a serem refletidos pelos educadores em sua prática e para vislumbrar possibilidades para promover uma elaboração do passado por parte daqueles que são por eles educados. O seu objetivo parece ser o de levar os educandos, tanto quanto os educadores, à autoconsciência a respeito do sofrimento provocado pela coação social e dos mecanismos que propiciam o potencial totalitário, mesmo nas chamadas democracias. Assim, procura reforçar a autoconsciência a respeito dos problemas da politização a que os indivíduos estiveram submetidos, responsável pelo aniquilamento da possibilidade de constituir-se efetivamente enquanto cidadãos e pelo afloramento do ressentimento contra a democracia, sustentado por uma subjetividade amorfa que procura identificar-se com o coletivo e com as instâncias de poder.

A sugestão a ser empreendida por essa forma de "educação política" arriscada pelo frankfurtiano é a de que poderia atuar como uma espécie de vacinação preventiva contra os truques da propaganda que alimentam o perigo objetivo do 
retorno ao nazismo e que atingem as disposições psíquicas das pessoas. Isso poderia ser realizado com

uma atuação conjunta daqueles psicólogos e pedagogos que não se esquivam da mais prioritária das tarefas profissionais em nome da objetividade científica poderia solucionar o problema da realização prática de um tal esclarecimento subjetivo. (Adorno, 1995a, p. 48).

Nesses termos, chama a atenção para que essa ação profissional conjunta não se resuma apenas aos métodos científicos convencionais e quantitativos - em que se priva da capacidade do pensamento e da especulação -, mas envolva propriamente uma aproximação do campo em que tais métodos possam ser refletidos criticamente com a filosofia.

Mesmo reconhecendo que essa atitude crítica e aquela reelaboração do passado, que pressupõem a inflexão em direção a si mesmo, não suscitem mais nas pessoas os efeitos esperados, ele parece querer provocar o que de humano (ou inumano) ainda resta no homem e a aspiração à liberdade que nele reside, apelando ao seu lado subjetivo e, mais especificamente, sensível.

Adorno (1995a) sugere que os indivíduos poderiam perceber o sofrimento provocado pelas coações sociais, a sensação de impotência em face da dominação social e o ressentimento que provocam contra a democracia. Nesse sentido, invoca a autoconsciência da natureza interna reprimida e a sua revolta mesma contra a sociedade política e a civilização como tendências que fazem sobreviver o que ocasionou o nazismo, mesmo nas democracias atuais. É por esse caminho que procura insistir na elaboração do passado, por mais que as pessoas estejam fechadas para tal, recorrendo ao que ainda resta de sensível à subjetividade destruída.

0 frankfurtiano afirma também que seria ineficaz lembrar às pessoas os ideais humanistas ou democráticos, invocando o seu comprometimento com eles, diante de toda repressão psicológica e do endurecimento necessário a sua sobrevivência no mundo atual. Então, o que talvez fosse mais eficaz nessa forma de "educação política”, segundo Adorno, seria reconhecer que

Estalingrado e os bombardeios noturnos não foram esquecidos a ponto de impossibilitar a compreensão de todos acerca da relação que existe entre 
uma política igual à que levou àquela situação e a perspectiva de uma terceira guerra púnica. (Adorno, 1995a, p. 48-49).

Apelando, assim, não à consciência das pessoas - que se encontra reificada e que se caracteriza por certa frieza no momento atual -, mas àquilo que lhes resta de sensivel, os estrondos ouvidos nos bombardeios, e que remete à percepção do sofrimento empreendido pelas coações e impotência sociais, é que Adorno acredita ser possível às pessoas que não se encontram fechadas a isso elaborar o passado e educar-se politicamente, cumprindo o que restou à "pedagogia da Aufklärung" na atualidade.

\section{Considerações finais}

Adorno revela implicitamente o sentido pedagógico postulado por sua filosofia e explicita o sentido ético em que preside sua reflexão acerca das possibilidades reais de uma "educação política" na atualidade. Uma "educação política" que ainda se alimenta da pedagogia da Aufklärung e de um ideal de democracia como uma antiga promessa ainda não cumprida e que poderia levar alguns indivíduos - e, gradativamente, a própria sociedade - à autoconsciência. Assim, o autor parece pressupor que, se houvesse alguma prática possível para ser desenvolvida na Alemanha e para ser privilegiada, nos anos 1960, ela estaria associada a essa concepção de "educação política" e à formação universitária.

Certamente, essa interpretação confirmaria a hipótese de Marcuse (1999) de que, nesse momento, Adorno havia se retirado da prática para preparar a consciência da necessidade de mudanças e a mudança necessária. Contudo, é provável também que Adorno pensasse que a sua prática formativa desenvolvida no interior da universidade tivesse possibilidades de ocorrer, não apenas porque seria o espaço adequado para promover essa forma de educação política - uma prática não destituída de teoria -, como também por haver ainda nessa instituição alguma liberdade e democracia. Talvez visse em sua atividade intelectual, sobretudo na sua prática docente e nos seminários de filosofia, um espaço em que os estudantes poderiam se desintoxicar da reificação do pensamento e da intolerância existentes nas formas de vida social existentes, além da especialização científica e do profissionalismo reinante na própria formação universitária. Recuperar essa face de seu pensamento foi o meio que encontramos para fazer jus ao seu pensamento crítico que, a despeito do que tenha 
sido mais cobrado e hostilizado por setores da esquerda, tem uma face educativa a ser explorada e ainda pode nos ensinar algo.

0 que pode nos ensinar na atualidade e faz parte dessa perspectiva filosófico-educacional presente em seu pensamento é que, seja para elaborar o passado, seja para pensar as questões que perpassam a ação pedagógica, o educador não é alguém que está emancipado e, como sujeito, se coloca em uma posição superior (epistemológica, moral e politicamente) à de seu aluno, como se estivesse protegido por alguma força superior a todos os mecanismos objetivos e subjetivos existentes que colocam em xeque a sua subjetividade. Não sendo possivel contrapor-se aos mecanismos objetivos, a inflexão em direção ao sujeito, proposta pelo frankfurtiano, respaldado no recurso à primazia do objetivo e em fazer de sua própria subjetividade objeto de seu pensar, nos termos expressos em seu ensaio sobre o sujeito e objeto ${ }^{8}$ e anteriormente reconstruído neste artigo, é uma atitude que preside a sua filosofia e que se encontra na base de toda reflexibilidade requerida para o seu exercício na educação. Nesse sentido, o educador se defrontaria com o evanescimento de sua própria subjetividade e com as razões que a ocasionam nas diferentes esferas da vida, inclusive na ação pedagógica, no mundo totalmente administrado.

Se a semicultura (a Halbbildung) se espraia em todas as esferas da vida, disseminando certa irracionalidade no âmbito público, a restrição da educação ao ensino ou ao treinamento profissional (Ausbildung) na escola a corrobora. Isso porque a escola não mais se ocupa da educação moral e política dos sujeitos, reiterando a semiformação socializada existente fora dessa instituição na qual atuam e, especificamente, qualificando-os para o mercado de trabalho; ou, quando se ocupa dessa tarefa, o faz formalmente, sem um comprometimento efetivo com a crítica e a formação de um eu capaz de resistir subjetivamente à sociedade totalmente administrada. Assim, a qualificação profissional assumida pela escola e a racionalidade instrumental que a preside apenas alimentam a semiformação socializada e a irracionalidade que dissemina na esfera pública, exceto se os sujeitos da educação escolar, ao se mostrarem abertos à reflexão sobre si mesmos e ao efetuarem-na, independentemente do lugar que ocupem (como educadores ou alunos), forem capazes de resistir

8. Na nota explicativa anterior justifiquei os motivos que me fizeram optar pelo que se consideram textos periféricos da obra de Adorno, tendo em conta a produção bibliográfica sobre 0 assunto no Brasil. Vale acrescentar, também, que, se considerássemos o caráter fragmentário de sua obra e aforismático de sua filosofia, estaríamos impedidos de conferir uma relação de totalidade ao seu pensamento, o que tornaria problemática essa discussão acerca do que é central ou periférico em termos metodológicos, exceto se desconsiderarmos o seu estilo, para incorporálos a métodos estruturais ou hermenêuticos, alheios à sua própria atitude crítica. Foi a essa incorporação que tentei fugir neste artigo, para fazer jus ao pensamento crítico e ao estilo ensaístico adorniano. 
a esses mecanismos objetivos de dominação na sociedade totalmente administrada.

Para o frankfurtiano, essa resistência só poderia advir da autorreflexão sobre a própria subjetividade evanescente que aflige tanto os educadores quanto os alunos, já que as possibilidades de reverter essas condições objetivas seriam praticamente inexistentes no presente. Por isso, ao abordar as características do trabalho pedagógico, além da crítica a tais condições de produção da semicultura e da indústria cultural, Adorno (1995a) argumenta pela existência de uma face "pessoal e afetiva" dessa atividade. 0 que diferenciaria a docência de outros ofícios, assim, seriam o conteúdo dessa face subjetiva do trabalho pedagógico e as tendências à barbárie que poderiam aí se manifestar, sendo, tanto estas quanto aquela, objetos privilegiados da autorreflexão crítica dos educadores.

Por meio dessa autorreflexão crítica sobre a própria atividade, os educadores poderiam evitar as injustiças cegas e a severidade exercida sobre os seus alunos, assim como tornar transparente e honesta essa relação, evidenciando os jogos de poder e os tabus que a compreendem. Os educadores poderiam, ainda, ao refletirem sobre o evanescimento de suas próprias subjetividades e o que são como sujeitos, encontrar elementos para, após essa espécie de experiência reflexiva sobre si mesmos, não apenas se tornarem mais sensíveis, como também atuarem no sentido da sensibilização dos alunos, como reconstruídos neste artigo, por meio de ações interdisciplinares, da elaboração do passado e de uma educação estética que só seriam efetivas naqueles que estivessem minimamente abertos e não completamente reificados. Assim, poderíamos aprender com Adorno, pelo exposto, não somente a necessidade desse trabalho autorreflexivo como sinônimo de uma filosofia da educação, com vistas a elucidar uma atitude crítica e ética presente na ação educativa, mas também um conjunto de indicações que, na prática, tornariam ainda possível ao educador uma educação política, mesmo que esta consista num incessante gesto de resistência àquilo que, no presente, promove a dominação e a barbárie. 


\section{Referências bibliográficas}

ADORNO, T. W. Dialética negativa. Rio de Janeiro: Jorge Zahar, 2009.

ADORNO, T. W. Educação e emancipação. São Paulo: Paz e Terra, 1995 a.

ADORNO, T. W. Palavras e sinais. Petrópolis: Vozes, 1995b.

ADORNO, T. W. Para qué aún la filosofía? In: ADORNO, T. W. Intervenciones. Caracas: Monte Ávila, 1969. p. 9-24.

ADORNO, T. W. Teoria da semicultura. Educação \& Sociedade, Campinas, ano XVII, n. 56, p. 388-411, dez. 1996. Papirus.

ADORNO, T. W. Terminológía filosófica I. Madrid: Taurus, 1983.

ADORNO, T. W. Trés estudios sobre Hegel. Madrid: Taurus, 1991.

ADORNO, T. W.; HORKHEIMER, M. Dialética do esclarecimento. 2.ed. Rio de Janeiro: Jorge Zahar, 1986.

BANNELL, R. I. Habermas e a Educação. Belo Horizonte: Autêntica, 2006.

BOUFLEUER, J. P. Pedagogia da ação comunicativa: uma leitura de Habermas. ljuí: Editora Unijuí, 1997.

DUARTE, R. A. P. Mímesis e racionalidade: a concepção de 'domínio da natureza' em Theodor W. Adorno. São Paulo: Loyola, 1993.

FREITAG, B. Teoria Crítica: ontem e hoje. São Paulo: Brasiliense, 1986.

GAGNEBIN, J. M. História e narração em W. Benjamin. São Paulo: Perspectiva, 1994.

GOERGEN, P. L. A crítica da modernidade e a Educação. Pro-Posições - Faculdade de Educação da Unicamp, Campinas, v. 7, n. 2 [20], p. 5-28, jul. 1996.

GOERGEN, P. L. Filosofia da Educação entre a integração e a emancipação. In: SEVERINO, A. J.; ALMEIDA, C. R. S.; LORIERI, M. A. (Org.). Perspectivas da Filosofia da Educação. São Paulo: Cortez, 2011. p. 135-149.

GONÇALVES, M.A.S. Teoria da ação comunicativa de Habermas: possibilidades de uma ação educativa de cunho interdisciplinar na escola. Educação \& Sociedade, Campinas, v. 20, n. 66, p. 125-140, abr. 1999.

HABERMAS, J. Theodor Adorno - Pré-história da subjetividade e auto-afirmação selvagem. In: FREITAG, B.; ROUANET, S. P. (Org.) Habermas. 3. ed. São Paulo: Ática, 1993. p. 139-50. (Coleção Grandes Cientistas Sociais, v. 5).

HERMANN, N. Educação e racionalidade: conexões e possibilidades de uma razão comunicativa na escola. Porto Alegre: EDPUCRS, 1996. (Coleção Filosofia, v. 36). 
LOUREIRO, I. M. (Org.). Herbert Marcuse: a grande recusa hoje. Petrópolis: Vozes, 1999.

MARCUSE, H. As últimas cartas. In: LOUREIRO, I. M. (Org.). Herbert Marcuse: a grande recusa hoje. Petrópolis: Vozes, 1999. p. 87-102.

MARKERT, W. L. Teoria Crítica e teoria educacional, Educação \& Sociedade - CEDES, Campinas, v. 3, n. 40, p. 402-418, 1992.

MATOS, O. F. C. Os arcanos do inteiramente outro: a Escola de Frankfurt, a melancolia e a revolução. São Paulo: Brasiliense, 1989.

PAGNI, P. A. Crítica, Aufklärung e Educação: considerações a partir de Foucault e Adorno. In: BUENO, S. F. (Org.). Teoria Crítica e sociedade contemporânea. São Paulo: Editora UNESP, 2009a. p. 225-244.

PAGNI, P. A. Da polêmica sobre a pós-modernidade aos 'desafios' lyotardianos. Educação e Pesquisa-USP, São Paulo, v. 32, p. 567-588, 2006 a.

PAGNI, P. A. Dimensão estética, linguagem e comunicação na experiência educativa: divergências entre Dewey e Adorno. Educação e Filosofia - UFU, Uberlândia, v. 23, p. 169-188, 2009b.

PAGNI, P. A. O filosofar na arte de educar entre o corpo e a infância: considerações a partir de Adorno e Lyotard. Childhood \& Philosophy, Montclair (USA); Rio de Janeiro: UM/UERJ, v. 1, n. 1, p. 3, 2005.

PAGNI, P. A. O problema do corpo na Educação contemporânea: paralelos entre Foucault e Adorno. Itinerários de Filosofia da Educação - GFE, Porto, v. 4, p. 175-192, 2006b.

PAGNI, P. A.; SILVA, D. J. A crítica à cultura e os desafios da educação após Auschwitz: uma leitura a partir da Teoria Crítica da Escola de Frankfurt. In: PAGNI, P. A.; SILVA, D. J. (Org.). Introdução à Filosofia da Educação: temas contemporâneos e história. São Paulo: Avercamp, 2007. p. 216-242.

PETRY, F. B. Filosofia como formação: seu ensino no pensamento de Theodor W. Adorno. Tese (Doutorado) - Programa de Pós-Graduação em Educação, Universidade Federal de Santa Catarina, Florianópolis, 2011.

PUCCI, B. Filosofia da Educação: para quê? Perspectiva - Revista do Centro de Ciências da Educação, Universidade Federal de Santa Catarina, Florianópolis, v.16, n. 29, p. 23-44, jan./jun. 1998.

PUCCI, B. (Org.). Teoria Crítica e Educação: a questão da formação cultural na Escola de Frankfurt. 3. ed. Petrópolis: Vozes, 2003.

PUCCI, B.; ALMEIDA, J.; LASTÓRIA, L. A. C. N. (Org.). Experiência formativa e emancipação. São Paulo: Nankin, 2009. 
PUCCI, B.; GORGEN, P.; FRANCO, R. B. (Org.). Dialética negativa, Estética e Educação. Campinas: Alínea, 2007.

PUCCI, B.; LASTÓRIA, L. A. C. N.; COSTA, B. C. G. (Org.). Teoria Crítica, Ética e Educação. Piracicaba: Editora da UNIMEP; Campinas: Autores Associados, 2001.

PUCCI, B.; OLIVEIRA, N. R.; ZUIN, A. A. S. Adorno: o poder educativo do pensamento crítico. Petrópolis: Vozes, 2000.

PUCCI, B.; OLIVEIRA, N. R.; ZUIN, A. A. S. (Org.). A educação danificada: contribuições à Teoria Crítica da Educação. Petrópolis: Vozes; São Carlos: EDUFSCAR, 1998.

PUCCI, B.; OLIVEIRA, N. R.; ZUIN, A. A. S. Teoria Crítica, Estética e Educação. Piracicaba: Editora da UNIMEP; Campinas: Autores Associados, 2001.

ROUANET, S. P. As razões do Iluminismo. São Paulo: Companhia das Letras, 1987.

Recebido em 04 de março de 2011 e aprovado em 30 de março de 2012. 
158

PROPOSICOES 20 NOV.indd 158 